\title{
Comparative Study of Endovenous Laser Ablation over Conventional Surgery of Varicose Veins of Lower Limbs
}

\author{
Dr. Sharad Sawant, Dr. Bhosale Dattatray, Dr. Anil Keskar
}

\begin{abstract}
Endovenous laser ablation (EVLA) of the great saphenous vein (GSV) is thought to minimize postoperative morbidity and reduce work loss compared with high ligation and stripping $(\mathrm{HL} / \mathrm{S})$. Patients with varicose veins due to GSV insufficiency were randomized to either EVLA $(980 \mathrm{~nm})$ or $\mathrm{HL} / \mathrm{S}$ in tumescent anesthesia. In our clinics, 50 varicosis patients were treated between August 2013 and September 2015. EVLA was applied in 25 cases and HL/S was applied in 25cases. Clinical features and demographic characteristics of the patients were summarized. EVLA procedure was done by $980 \mathrm{~nm}$ diode laser (Ceralas D 980 , Biolitec) at continues mode with $15 \mathrm{~W}$ energy. Patient visits were done at post-operative 10th day, 6th month, 1st year and 2nd year. Routine physical examination and Doppler USG assessments were performed at these visits. EVLA and HL/S procedures were done in complete success in all cases at both groups. All cases were invited for control visits. When complications developed after procedures were evaluated; no infection, hematoma or parenthesis were observed in EVLA group. However in HL/S group; infections, hematomas and parenthesis were observed in 6,4 and 2 cases respectively. In terms of treatment success, there was no recurrence in EVLA procedure while recurrence rate after conventional surgery found in 3 cases. In terms of post-op complication, EVLA method was associated with significantly less parenthesis, hematoma and pain. EVLA method is a method as effective and safe as standard treatment. However, when a long term result of this method is shown completely, its effectiveness will be cleared and its clinical utility will be established.
\end{abstract}

Keywords: Endovenous laser ablation, great saphenous vein, high ligation and stripping

\section{Introduction}

Venous insufficiency at lower extremities may result with clinical problems from cosmetic issues to ulcerations. When the frequency of venous insufficiency and its related problems are considered besides their diversity, it is encountered as a public health issue. This pathology is reported to affect $40 \%$ of the women and $20 \%$ of the men $(1,2)$.

General complaints related to venous insufficiency depends on the severity of the Insufficiency and accompanying pathologies. Discoloration, pain, cramps, itching, edema and ulcerations at legs are symptoms accompanying to venous insufficiency (3). While major risk factors are age and family history for both sexes, pregnancy is an additional risk factor for women (4). Besides, standing for long periods, obesity and female gender are reported as risk factors (5).

Until recently, the standard treatment consisted of ligating vena saphena magna (VSM) at saphenofemoral junction, stripping below knee and mini phlebectomies. Additionally, branches of VSM at junction are ligated and divided and thus, the recurrence is aimed to be prevented (6). With the development of minimal invasive techniques in the past 10 years, the usage of laser energy came to the fore for the endovenous thermal ablation of VSM. Radiofrequency ablation and ultrasound guided foam sclerotherapy methods have emerged. Postoperative follow up results of those 3 techniques are still debating and continued to be evaluated (7-9). In our study we compared VSM high ligation and stripping (HL/S) to the endovenous laser ablation (EVLA) procedure in cases with varicosis due to VSM insufficiency. We aimed to explore advantages and disadvantages of both procedures for the short term results.

\section{Materials and Methods}

In our study, 50 patients with varicose veins were treated between August 2013 and September 2015. EVLA was applied in 25 cases and HL/S was applied in 25 cases. Patients reported they had complaints for more than 3 years. Most frequent complaints were pain $(\mathrm{n}: 45)$ and cramps (n:43).

While varicose dilatations were obvious for all cases, skin discolorations were observed in 5 cases. Venous ulceration was also present in 3 cases. The study was planned as a retrospective study. Physical examination and venous Doppler USG were performed in outpatient basis for the patients admitted to the outpatient clinics. Deep venous system, duration and degree of reflux at VSM, perforators and vena saphenaparva were evaluated by Doppler USG. Patients with deep venous thrombosis (DVT), perforating venous insufficiency, deep venous insufficiency, thrombophlebitis, peripheral artery disease were excluded.

All procedures were done by 2 experienced surgeons at the operation room. In $\mathrm{HL} / \mathrm{S}$ procedure the incisional dimensions were $2 \mathrm{~cm}$ and $4 \mathrm{~cm}$ at ankle level and inguinal region respectively. VSM and its were branches ligated and divided at saphenofemoral junction. It use followed by complete stripping and mini- phlebectomy procedure. HL/S procedure was performed under regional anesthesia.

EVLA procedure was done by $980 \mathrm{~nm}$ diode laser (Ceralas D 980, Biolitec) at continues mode with $15 \mathrm{~W}$ energy with 80-90 julespr $\mathrm{mm}$. Covered catheter capable of radial emission was used. The catheter was placed in VSM by percutaneous way, but in 5 cases, the catheter placement necessitated cut-down. Catheter was advanced until $2 \mathrm{~cm}$ below of the saphenofemoral junction. EVLA procedure was performed under tumescent anesthesia and mild sedation. A homogenous perivenous mantle was formed 


\section{International Journal of Science and Research (IJSR) \\ ISSN (Online): 2319-7064 \\ Index Copernicus Value (2013): 6.14 | Impact Factor (2014): 5.611}

along VSM by tumescent anesthesia. Tumescent anesthesia was $200 \mathrm{~mL}$ and consisted of $4 \mathrm{mg}$ lidocain, $4 \mathrm{mg}$ adrenaline, $0.5 \mathrm{mg}$ dinatrium EDTA, $1.68 \mathrm{~g}$ sodium bicarbonate and $\mathrm{NaCl}$.

The leg of the patient was wrapped in pressured bandage following the procedure and the bandage was removed after 2 days and middle pressure varsity socks were worn. All patients were kept under clinical observation for 18 hours. Nonsteroidal anti-inflammatory drugs were prescribed for discharged patients and recommended to be used when symptoms occurred. Patient visits were done at postoperative 10 th day, 6 th month, $1^{\text {st }}$ year and $2^{\text {nd }}$ year. Routine physical examination and Doppler USG assessments were performed at these visits.

All parameters were evaluated in both groups. Continuous variables were tested with Student's t test and MannWhitney $\mathrm{U}$ test. The categorical variables were tested with the $\mathrm{Z}$ test.

\begin{tabular}{|c|c|c|c|}
\hline & EVLA & HL/S & $\mathrm{p}$ value \\
\hline Infection & 1 & 6 & 0.042 \\
\hline Hematoma & 0 & 4 & 0.037 \\
\hline Paresthesia & 0 & 2 & 0.148 \\
\hline Recurrence & 0 & 3 & 0.074 \\
\hline
\end{tabular}

EVLA, Endovenous laser ablation.

HL/S: High ligation and stripping

\section{Results}

EVLA and HL/S procedures were done with complete success in all cases at both groups. All cases were invited for control visits. At postoperative 10th day, all patients were evaluated; When the complications developed after procedures were evaluated; no infection, hematoma or paresthesis were observed in EVLA group. However in HL/S group, infections, hematomas and paresthesis were observed in 6,4 and 2 cases respectively. In contrast, only 1 case found to be infected in EVLA group.

When the groups were evaluated for treatment efficacy, there was no recurrence in EVLA procedure while recurrence after conventional surgery found in 3 cases.

\section{Discussion}

HL/S method is most frequently used surgical treatment method worldwide for the treatment of varicosities (6). However, a rapid development was achieved in minimal invasive varicose vein surgery in the recent 10 years. Novel methods such as EVLA, radiofrequency ablation (RFA), foam sclerotherapy became popular as alternatives to this surgical procedure. All of these methods have been compared to each other in various studies. In studies comparing RFA and HL/S methods RFA method has been reported to have significant advantages (10-12). In a study comparing HL/S and EVLA methods, EVLA was reported to result with less edema and blisters but no other significant differences found between (13). In comparison of foam sclerotherapy to $\mathrm{HL} / \mathrm{S}, \mathrm{HL} / \mathrm{S}$ procedure was reported to be superior (14).
In our study, when the groups were evaluated for treatment efficacy, there was no recurrence in EVLA procedure while recurrence after conventional surgery found in 3 cases.

When post-op complications were evaluated, hematoma and paresthesis were significantly higher in HL/S group. In literature Hartmann et al. reported pares thesis ratio reached to $40 \%$ in complete stripping and Uncu reported in complete stripping, paresthesis healed with time and became permanent in $2 \%$ of the patients $(15,16)$.

Rasmussen et al. compared EVLA and HL/S methods for various parameters in a randomized prospective study. They recorded quite high pain ratios in HL/S group at early period by pain scorings. However they reported that the pain ratios reached lowest limit at $3^{\text {rd }}$ month and coursed at similar ratios in both groups (17). Results of our study are comparable with these data. Pain complaint was determined at quite high ratios in HL/S group. Tumescent anesthesia in the EVLA group was reported to have impact on this difference (17).

When recurrence rates were examined there was significant difference between both groups at post-op 1st and 2nd years. Recurrence rate was observed to be higher in the HL/S group. Various results were reported in literature for recurrence rate. There are publications reporting $7 \%$ recurrence after 24 months follow up besides publications reporting $10 \%$ recurrence rate in 12 months for the cases in whom ablation was performed by the EVLA method $(18,19)$

\section{Conclusion}

In terms of treatment success, EVLA procedure is better than HL/S method. In terms of post operative complication, EVLA method was associated with significantly less infection, paresthesis, hematoma and pain. EVLA method is more effective and safe HL/S method. When long term results of this method are shown completely, its effectiveness will be cleared and its clinical utility will be established.

\section{References}

[1] Callam M.J. Epidemiology of varicose veins Br J Surg 1994; 81: 167-173.

[2] Slagsvold CE, Stranden E, Rosales A. Venous insufficiency in the lower limbs Tidsskr Nor Laegeforen. 2009 Nov 5; 129: 2256-2259.

[3] Evans CJ, Fowkes FG, Ruckley CV,et al. Prevalence of varicose veins and chronic venous insufficiency in men and women in the general population: Edinburgh Vein Study. J Epidemiol Community Health 1999; 53: 149153.

[4] Carpentier PH, Maricq HR, Biro C, et al. Prevalence, risk factors, and clinical patterns of chronic venous disorders of lower limbs: a population-based study in France J Vasc Surg 2004; 40: 650-659.

[5] Jawien A. The influence of environmental factors in chronic venous insufficiency. Angiology 2003; 54 1: 19-31.

[6] National Institute for Clinical Excellence-NICE.

\section{Volume 4 Issue 11, November 2015}




\section{International Journal of Science and Research (IJSR) \\ ISSN (Online): 2319-7064}

Index Copernicus Value (2013): 6.14 | Impact Factor (2014): 5.611

Interventional procedures overview of endovenous laser treatment of the long saphenous vein 2003.

[7] Min RJ, Khilnani N, Zimmet SE. Endovenous laser treatment of saphenous vein reflux: long-term results. J VascIntervRadiol 2003; 14: 991-996.

[8] Teruya TH, Ballard JL. New approaches for the treatment of varicose veins. Surg Clin North Am 2004; 84: 1397-417.

[9] Tessari L, Cavezzi A, Frullini A. Preliminary experience with a new sclerosing foam in the treatment of varicose veins. Dermatol Surg 2001; 27: 58-60.

[10]Lurie F, Creton D, Eklof B, et al. Prospective randomized study of endovenous radiofrequency obliteration (closure procedure) versus ligation and stripping in a selected patient population 2003; 38: 207 214.

[11]Lurie F, Creton D, Eklof B, et al. Prospective randomised study of endovenous radiofrequency obliteration (closure) versus ligation and vein stripping (EVOLVeS): two-year follow-up. Eur J Vasc Endovasc Surg 2005; 29: 67-73.

[12] Hinchliffe RJ, Ubhi J, Beech A, et al. Braithwaite BDA prospective randomised controlled trial of VNUS closure versus surgery for the treatment of recurrent long saphenous varicose veins. Eur J VascEndovascSurg 2006; 31: 212-218.

[13] De Medeiros CAF, Luccas GC. Comparison of endovenous treatment with an $810 \mathrm{~nm}$ laser versus conventional stripping of the GSV in patients with primary varicose veins. DermatolSurg 2005; 31: 16851694.

[14] Wright D, Gobin JP, Bradbury AW, et al. Varisolve polidocanolmicrofoam compared with surgery or sclerotherapy in the management of varicose veins in the presence of trunk vein incompetence: European randomized controlled trial. Phlebology 2006; 21:190.

[15] Hartmann K, Klo de J, Pfister R, et al. Recurrent varicose veins: sonography-based re-examination of 210 patients 14 years after ligation and saphenous vein stripping. Vasa 2006; 35: 21-26.

[16] Uncu H. Should complete stripping operation to the ankle be avoided in the treatment of primary varicose veins due to greater saphenous vein insufficiency? Acta Cir Bras 2009; 24: 411-415.

[17] Rasmussen LH, Bjoern L, Lawaetz M, et al. Randomized trial comparing endovenous laser ablation of the great saphenous vein with high ligation and stripping in patients with varicose veins: short-term results. J VascSurg 2007; 46: 308-315.

[18] Proebstle T, Gul D, Lehr H, et al. Infrequent early recanalization of greater saphenous vein after endovenous laser treatment. Journal of Vascular 2003; 38: 511-516.

[19] Al Samaraee A, McCallum IJ, Mudawi A. Endovenous therapy of varicose veins: A better outcome than standard surgery? Surgeon 2009; 3:186.

[20] Theivacumar NS, Della grammaticas D, Beale RJ, et al. Fate and clinical significance of saphenofemoral junction tributaries following endovenous laser ablation of great saphenous vein. Br J Surg 2007; 94: 722-725.

[21]Demirkili9 U. Endovenoz Lazer Tedavisinde Son Geli§meler Turkiye Klinikleri J Cardiovasc SurgSpecial Topics 2009; 2: 36-38.
[22] Prince EA, Ahn SH, Dubel GJ, et al. An investigation of the relationship between energy density and endovenous laser ablation success: does energy density matter?J Vasc Interv Radiol 2008; 19: 14491453. 